\title{
Role of Natural Products in Parkinson's Disease
}

\author{
Arjun Singh ${ }^{*}$, Pooja Sharma ${ }^{1,2}$, Dinesh Kumar ${ }^{1}$ \\ ${ }^{1}$ Sri Sai College of Pharmacy, Manawala, Amritsar-143115, Punjab, India \\ ${ }^{2}$ Department of Pharmaceutical Sciences and Drug Research, Punjabi University Patiala, Punjab, India
}

Address for Correspondence: Arjun Singh; lovepreet6212@gmail.com

Received:

01.03.2019

Accepted:

25.03.2019

Keywords

CNS Disorders;

Natural Products;

Medicinal Plants.
ABSTRACT: Parkinson's disease (PD) is the world's second most common neurodegenerative disorder, which can significantly impair the quality of life, create dependency and trigger premature mortality of affected individuals (1). The prevalence rate of PD is 0.5-1\% among people aged 65-69 years and 1-3\% among those aged 80 and above. Bioactive derivatives of plants such as flavonoids, stilbenoids and alkaloids possess potent anti-oxidative and anti-inflammatory properties that are of considerable interest for the treatment of PD. The chemical constituents derived from herbs, fruits, vegetables, and spices against PD relies on the presence of flavonoids, steroidal lactones, ginsenosides, alkaloids, caffeine, stilbenoids, ginkgolides, bilobalides , xanthones, saponins, oligosaccharide esters, glycosides isoflavonoids, polymethoxyflavones, catechins, anthocyanins, S- Allylcysteine, lycopene, thymoquinone, sesaminoids, curcuminoids, zingerone, eugenol, and chrysotoxine. enoids, catechols and glycosides. Flavonoids, the major polyphenol group, consist of aromatic rings possessing a phenolic hydroxyl group Its based on their alkylation, glycation, and hydroxylation patterns, flavonoids are classified into flavones, flavanones, flavanonols, flavanols, anthocyanidins, and isoflavones. Anti-Parkinsonian compound are present in medicinal plants like Camelia sinesis (Green tea), Withania somnifera and Ginseng. () 2019 iGlobal Research and Publishing Foundation. All rights reserved.

Cite this article as: Singh, A.; Sharma, P.; Kumar, D. Role of Natural Products in Parkinson's Disease. Indo Global J. Pharm. Sci., 2019; 9(2Suppl.): 148. DOI: http://doi.org/10.35652/IGJPS.2019.92S46.

Indo Global Journal of Pharmaceutical Sciences( ISSN 2249 1023; CODEN- IGJPAI; NLM ID: 101610675) indexed and abstracted in CrossRef (DOI Enabling), UGC CARE Journal List, EMBASE(Elsevier), National Library of Medicine (NLM) Catalog, ResearchGate, Publons, CAS (ACS), Index Copernicus, Google Scholar and many more. For further details, visit http://iglobaljournal.com

This is a special issue as an outcome of 'RAPSCON-2019' sponsored by APTI and organized by Sri Sai College of Pharmacy, Manawala, Amritsar, Punjab, India. Relaxation offered in journal format. 